\title{
O personagem encontra o autor
}

Wilson Figueiredo

A TÉ QUE um escritor mineiro, encantado pelo que lia e ouvia, se dispusesse a levantar as circunstâncias humanas e sobrenaturais em meio às quais viveu Jayme Rojas de Aragón y Ovalle (18941955 ), o personagem esteve à disposição de quem se interessasse. Ninguém se apresentou. Meio século depois de sua morte, tinha de ser mineiro, Humberto Werneck percebeu a última oportunidade antes de se dissipar o efeito especial do personagem exclusivo de um tempo que deixou marcas. A credencial do biógrafo foi a autoria de $O$ desatino da rapaziada, no qual levantou os antecedentes juvenis do grupo de escritores da segunda geração modernista em Minas, por sinal irmanados na admiração por Ovalle. O santo sujo é a biografia levantada por um escritor que se encontrou no jornalismo. Foi com o que um e outro - o jornalista e o escritor - têm de melhor que Humberto Werneck captou, isento de interpretações, o eco das lembranças de Ovalle entre os últimos personagens daquele Rio cujas águas também não passam duas vezes pelo mesmo lugar. E evitou que se dissipasse a memória da real belle époque da vida noturna carioca, antes da perda, pelo Rio, da condição de capital da República.

Em Minas, a loucura mansa, entendida como doença de família, dispensava a mão da ciência. Tratava-se com discrição, mistério e convivência. De poeta e de louco, cada qual se contenta com pouco, e, no caso de Jayme Ovalle, o personagem portava dose dupla. Foi poeta e esquisitão pelos critérios da época. Era paraense, mas seu biógrafo é minei- ro. Minas tem também uma cidade com o nome de Pará, com a ressalva de ser “de Minas", que se contenta, em matéria de armas de fogo, com o armamento da Polícia Mineira. Nos anos 1920, quando a vida no Brasil ainda guardava muito do século XIX, Jayme Ovalle, num dos seus improvisos iluminados, criou o exército do Pará, para prestação do serviço literário obrigatório. Veio a ser, desde logo, uma interpretação autorizada da variedade humana, segundo o temperamento e os sinais exteriores de cada um. Uma espécie de doutrina para uma escola inferior de guerra no plano cultural, batizada de Nova Gnomonia, para se distinguir da ciência que identificava, nas feições inatas, a característica das pessoas. A velha gnomonia, em sinal de desgosto, aposentou-se.

A Nova Gnomonia veio a ser um sucesso e, se não foi oficializada, ainda terá reconhecimento acadêmico, por ser ciência genuinamente brasileira para padrões brasileiros de comportamento. $\mathrm{O}$ que bloqueou sua extensão além do território nacional terá sido a reação indignada dos escritores e artistas provenientes do Norte do Brasil, quando a viagem de vinda para o Rio só se fazia pelo mar. Não havia retorno triunfal para quem não se consagrasse em alguma especialidade, fosse sucesso pessoal, glória literária ou poder político. A revelação gerou o mal-entendido que implicou todos os devotados à vitória pessoal como razão suprema da vida: "Onde chegam, vencem". O nortista, como era genericamente chamado quem chegava da Bahia para cima, reagiu com razão por se sentir 
desconfortavelmente tachado de carreirista ao se destacar na competição social. Quem vinha do Norte para o Sul passava a impressão de aceitar a obrigação de fazer sucesso ou desaparecer para sempre. Nada de pessoal, porém: o exército do Pará era metáfora para caracterizar o êxito federal de provincianos. Mas o sucesso popularizou a definição, ganhou contorno de caricatura e indispôs os ânimos nortistas contra intelectuais sulistas. A teoria de Ovalle se espalhou com a contribuição valiosa de Manuel Bandeira e outros aplicados à gaia ciência nascida e desenvolvida na vida boêmia. Foi, do ponto de vista militar, o momento em que a história do Brasil pareceu copiar a dos Estados Unidos no episódio da Secessão americana. A questão acabou resolvida, graças ao avião e à entrada em cena dos escritores nordestinos, que não puseram a carapuça nem o quepe paraense.

O exército do Pará prescindia de comando e hierarquia. Os escritores nortistas que venceram no Sul se defenderam com brio, mas a metáfora sobreviveu a despeito do alto comando intelectual que a patrocinou. Com o tempo, declinou o clima bélico. A questão se resolveu quando os escritores nordestinos entraram em cena e arquivaram a prestação do serviço militar entre aspas. Quem se interessar pode se inteirar de tudo nas Crônicas da Provincia do Brasil, de Manuel Bandeira, para revisitar o histórico da criação, a elaboração da estrutura sociológica do paraísmo, a contribuição de Jayme Ovalle e a reação em cadeia dos alcançados pessoalmente pela metáfora. O pernambucano Manuel Bandeira foi o pacificador da questão militar que abalou a inteligência brasileira. A biografia do paraense Ovalle, pelas mãos mineiras de Humberto Werneck, contribuiu para situar o episódio definitivamente à margem da história da literatura brasileira. $\mathrm{O}$ interessado pode encontrar brasas debaixo das cinzas da polêmica e acender o cigarro que sobrevive graças ao consumo feminino. Em O santo sujo, um capítulo historia o nascimento, a criação e a formulação das bases de um exército que foi parar na categoria da Batalha de Itararé, que ia ser a maior da história do Brasil, mas não houve.

No que respeita ao desempenho do poeta e compositor musical Jayme Ovalle, daí por diante a produção ficou escassa para a fartura que o autor prometia, além de confirmar a baixa disposição e o insuficiente preparo para o exercício das letras e das notas musicais. Esse desencontro entre o poeta e os versos, e entre o compositor e as notas, resultou em estatística modesta e sobreviveu na hipótese de $O$ santo sujo, que era "só uma idéia" de vir a ser um livro escrito por Ovalle e acabou, por absoluta omissão, sendo ele próprio o personagem, por obra e graça de Humberto Werneck.

Jayme Ovalle tinha uma aura, mais pressentida do que visível, e uma telha de menos, na maneira de ser, arejava favoravelmente a vida do solteirão por acaso (presente em tudo que se passava com ele). Era improviso e sonho. Funcionário público da Alfândega, considerado exemplar, o boêmio "era extremamente criterioso no trato do dinheiro", segundo depoimento da sua mulher, Virginia Peckham. Com as sobras do salário de alto funcionário federal, comprava títulos da dívida pública brasileira. Boêmio, mas rigoroso nos gastos pessoais e no prazer de economizar (outro ponto de contato com os mineiros), não teve pressa em se casar, mesmo metaforicamente. 
Vivia, como então se dizia, em concubinato com a noite carioca. $\mathrm{O}$ material foi devidamente levantado pelo biógrafo, com todo respeito pela memória do personagem. Era por aí, em bares pelo centro da cidade, que mantinha em dia (a rigor, na noite) a genialidade e reabastecia o cordial convívio dos que o freqüentavam. Vinicius de Moraes, que chegou tarde à roda de amigos noturnos, o considerava "o homem mais próximo da genialidade" que conhecera. Os novos convertidos de Ovalle serão fartamente servidos e poderão se multiplicar fagueiramente na tradição da vida noturna carioca, à qual o biografado aderiu aos 20 anos e só se retirou depois de casado com Virginia, que ia entrar na sua vida de maneira ovalliana e, de certo modo, continuar na viuvez as vicissitudes que provou antes e depois.

Ao chegar à vida adulta, Ovalle - já funcionário graduado da Alfândega - foi morar numa casa pequena alugada na Rua Conde de Lage, onde se concentrava o nível mais alto das mulheres da noite, não longe do epicentro noturno na Lapa dos anos 1940. A crônica pessoal de Ovalle naquele endereço foi reconstituída por Humberto Werneck, com método e sem preocupação de outra natureza que não fosse mostrar um poeta e criador de música que deixou pendente, como nos versos de Bandeira, "uma vida inteira que podia ter sido e que não foi" o que ele e seus amigos esperavam. Como, porém, conciliar as paixões sucessivas e as noites do Rio com o catolicismo assumido? De certo modo, Ovalle contribuiu para modernizar, por não se escandalizar, os costumes provincianos residuais. Di Cavalcanti disse (em versos): "Éramos personagens de romances que nunca foram escritos".
De dia ou de noite, o Rio era denso no centro e deixava, com exclusividade, os bairros residenciais às famílias. Ovalle estava sozinho na arte de contar casos. Era um dom exclusivo dele. Di observou que ninguém conseguia repetir o sucesso dele em contar história. A graça era intransferível. Mas os episódios em que era personagem tinham vida própria, não dependiam do narrador.

A reforma dos costumes veio para valer depois da Segunda Guerra. Naturalmente, pelas mãos do progresso urbano, socialmente tolerante e leigo. Werneck reconstituiu com rigor objetivo do jornalismo a passagem de Ovalle pela vida e pela cultura. Não teve parcimônia em destacar as opiniões críticas que lhe reconheciam o talento, mas não o eximiam de falta de preparo, tanto para a poesia como para a criação musical, cujo saldo de qualidade sobreviveu apenas em 33 composições, entre as quais umas poucas obras-primas. Pouco para seu potencial que se revelou no vôo do $A z u l a \tilde{o}$, nome de três criações musicais com autorias diferentes, mas com a mesma letra de Manuel Bandeira. O poeta pernambucano, por sinal, dividiu com outro poeta, Augusto Frederico Schmidt, o convívio de perto com o personagem desde o começo da vida adulta. (Schmidt casou-se com uma sobrinha de Ovalle.) O pintor Di Cavalcanti, apesar de boêmio convicto, foi severo na observação sobre o amigo Ovalle: "Nunca terminou coisa nenhuma". Nas composições musicais, ficava nos primeiros acordes. Na poesia, partia de uma idéia, mas não decolava com as primeiras palavras. $\mathrm{O}$ resto seria com os outros. O poeta Dante Milano depõe que, "quando tentava escrever, as palavras lhe fugiam", mas atenuou com a observação genérica de que "há muito 


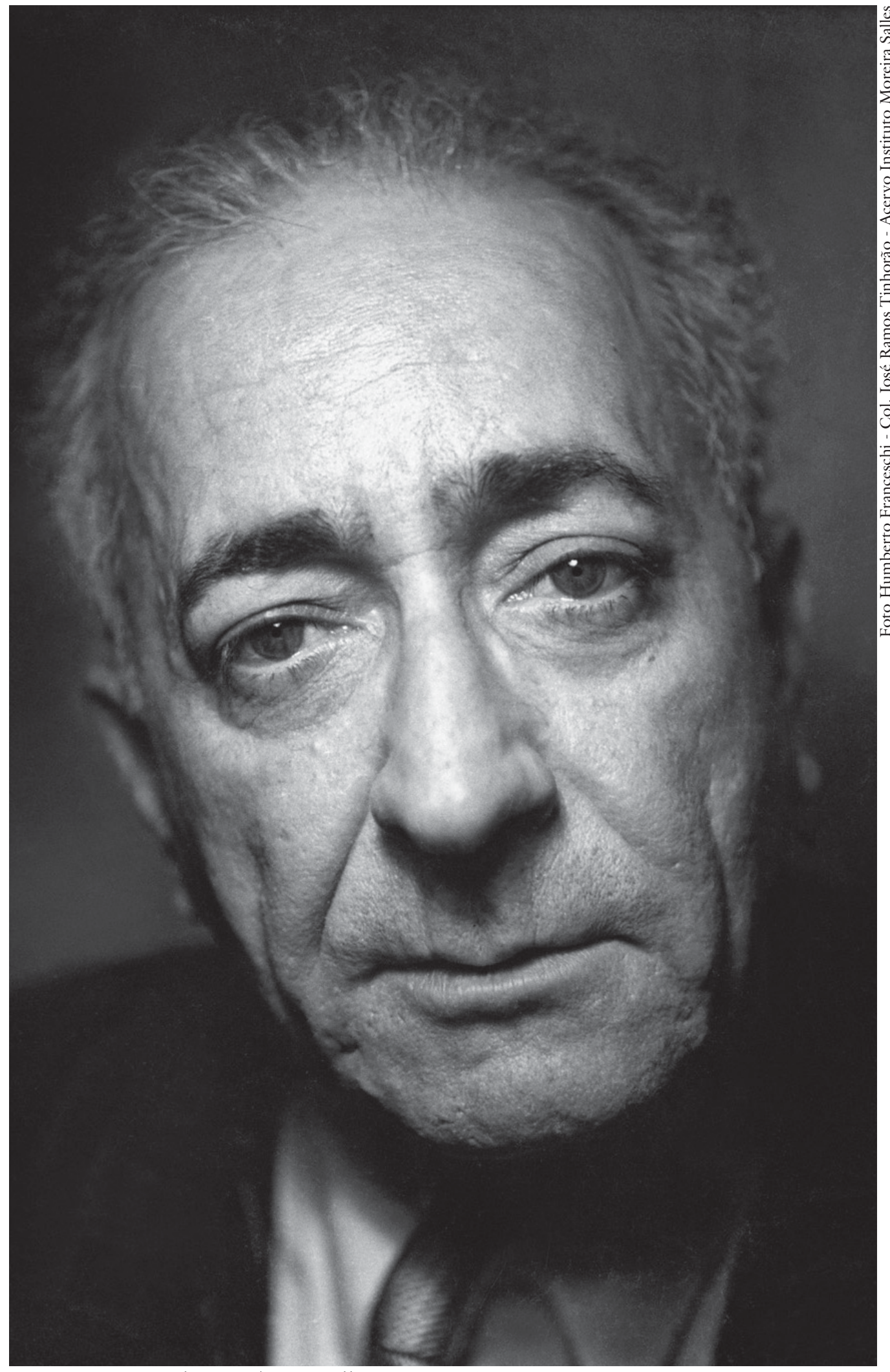

Jayme Rojas de Aragón y Ovalle (1894-1955). 
dessa poesia só imaginada, nunca escrita". E arrematou: "Quem não acredita na inspiração não conheceu Jayme Ovalle”. Era a inspiração seguida do horror à transpiração para elaborar a melhor forma.

O caso dos Poemas ingleses e de The Foolish Bird diz tudo: ele teve a idéia em Londres, anunciou a intenção, esboçou a concepção e ficou por aí, até que, mais tarde, confiou à própria mulher, a americana Virginia Peckham, a missão de traduzir o que mal estava esboçado em português. Ovalle sabia menos inglês do que o português que Virginia falava. Na opinião dela, o inglês dele dava "para as necessidades mínimas". Os poemas, porém, nunca foram dados por concluídos. Eis Jayme Ovalle, no esplendor do método em que se perdeu e deixou uma lenda sem saldo substancial.

O resultado final foi a prevalência do poeta que não fazia versos (ou os elaborava apenas mentalmente), enquanto a vida transcorria um degrau acima do natural e um abaixo do sobrenatural: o talento criador era captado e retransmitido, em ondas curtas e longas, na boêmia carioca, sem prejuízo da assumida fé religiosa. Ficou apenas o título por ele reservado para outra obra que nem começaria, História de São Sujo, e que devolveu o autor à condição de personagem, pela mesma inércia que o travou a vida toda na hora de criar. Sem ao menos um parágrafo escrito por Ovalle, o livro foi redigido com o que Humberto Werneck, para aproveitar o título, levantou sobre sua vida puxada ao sobrenatural. Botou em ordem o personagem marcado pelo imprevisível. Numa visita matinal a Manuel Bandeira, solteirão convicto, Ovalle não conteve as lágrimas ao ver o poeta preparar seu café matinal como um ato de contrição. Mas a atriz Luz del Fuego não encontrou dificuldade em convencê-lo a ficar com a enorme serpente com que se apresentava no palco, enquanto fazia uma longa viagem.

O poeta que não "escreveu poesia" veio a ser o personagem insubstituível de uma época que o biógrafo localizou em escavações do modernismo brasileiro. A incidência do sobrenatural que rege $O$ santo sujo - a vida da Jayme Ovalle teve todo o respeito da parte do escritor mineiro: Werneck situou-se na isenção dos agnósticos que, não sendo capazes de desmontar objetivamente a existência de Deus, também não encontram argumentos para afirmá-la. Mas não era esse o território de Ovalle, que se situava além da realidade e aquém do sobrenatural. Levava a numerologia ao pé da letra (ou, melhor, dos números). O biógrafo se move fora da questão sobrenatural com uma distância realçada pelo encantamento boêmio do personagem, que não perdia o tradicional Baile dos Artistas no Carnaval carioca.

Sendo da terceira geração de escritores mineiros (a primeira foi dos que nasceram pouco antes ou logo depois da passagem do século XIX para o XX, e viveram o Movimento Modernista nos anos 1920), Humberto Werneck se iniciou na literatura com a admiração pelos "Quatro mineiros do Apocalipse" - a segunda geração do modernismo mineiro - quando já migravam para o Rio. No seu $O$ desatino da rapaziada, historiou o perfil dos grupos de candidatos a poetas e prosadores na Belo Horizonte dos anos 1940 e 1950. A cada geração se repetia a diáspora. Ao esgotarem as possibilidades locais, as vocações batiam asas e abriam espaço para a geração seguinte, com as mesmas disposições que se con- 
verteriam em sucessos, acomodações e desistências. Uma parte da terceira geração modernista mineira se encaminhou para o jornalismo profissional, a partir de São Paulo. Todos se encontrariam com o sucesso, como jornalistas e escritores, e garantiram sucesso na significativa contribuição à reforma da imprensa paulista. Humberto Werneck encontrou em Fernando Sabino, Otto Lara Resende, Paulo Mendes Campos e Hélio Pellegrino (especialmente no primeiro) o culto de Jayme Ovalle como figura humana e autor de frases pessoais e originais. Era o caldo de cultura das intermináveis conversas de que se ocupavam, quando não tinham nada melhor para divergir sobre letras, política, cinema, Brasil, socialismo e cristianismo àquela altura na capital de Minas. Desde O encontro marcado, o autor localizou impressões digitais de Jayme Ovalle já nas crônicas dos anos que os dois passaram juntos nos anos 1940 em Nova York. São muitas as referências e episódios que fizeram de Fernando Sabino o guia credenciado do ovallismo, entre sombras místicas e iluminações proporcionadas pelo personagem real: "Não sabia telefonar, pôr selo em carta, redigir telegrama, e nem mesmo decifrava sua caligrafia".

À sombra da maneira de ser do seu personagem, Humberto Werneck monitorou a duplicidade do talento criador e a falta de conhecimento da arte de escrever, sem atingir a figura humana que ocupou lugar de destaque na primeira geração modernista, com a criatividade $\mathrm{e}$ as deficiências artesanais que o desqualificaram. Werneck chegou a Ovalle pela mão de Fernando Sabino, mas depois que este refez a primeira impressão desagradável por sua presença, como penetra, num jantar a Neruda em seu apartamen- to no Rio, em 1945. Achou que Ovalle, afinal, não era "tão chato" quanto lhe parecera. Entenderam-se e, daí por diante, se tornaram parceiros da noite e do sobrenatural, nos três anos compartilhados em bares de Nova York. Fernando morreu como discípulo e "consultor de pequenas causas" do personagem que passava, direta e indiretamente, por suas crônicas e seus romances. Outra vertente foi Manuel Bandeira, cujas crônicas mais antigas são marcos de referência do ovallismo e, especialmente, da Nova Gnomonia. Mas "ninguém escreveria mais do que Sabino sobre Ovalle", assinalou Humberto Werneck, que sentiu influência dele no humor do cronista e mesmo do diplomata que é o duplo dele no $O$ encontro marcado.

Abre o livro, não por acaso, a coincidência da morte do pai de Jayme Ovalle, a bordo de um navio nas costas da África e a caminho da Espanha, em viagem de negócios, com o estilhaçamento inexplicável do grande espelho de cristal na parede da casa em que moravam os Ovalle em Belém do Pará. A partir desse episódio, na época em que a borracha da Amazônia descia do apogeu à ruína, a mãe viúva optou pela vinda para o Rio em busca de horizonte para a família e de "ricos casamentos" para as quatro lindas filhas.

O roteiro inclui, na última fase, a cota de Virginia Peckham que, aos 20 anos, chegou tardia e casualmente, como convinha ao personagem, à vida de Jayme Ovalle. E ainda estendeu o fio do destino à filha Mariana. Jayme e Virginia conheceram-se na inauguração de uma exposição de pintura em Nova York. Ele, de monóculo, fumava o tempo todo, segundo Virginia. Ele também reparou nela e, depois de várias manobras, ao fim 


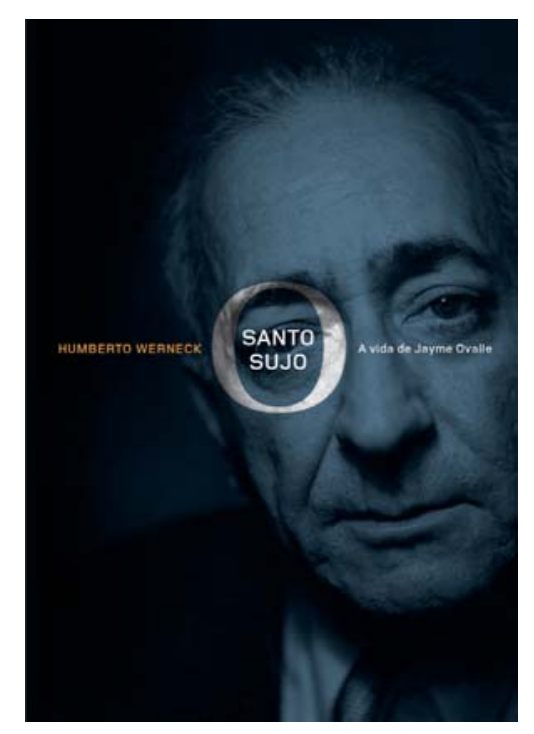

WERNECK, Humberto. O santo sujo a vida de Jayme Ovalle. São Paulo: CosacNaify, 2008. 400p.

e ao cabo, foram jantar com um grupo de retardatários com que ela se protegeu. Nas despedidas, Ovalle ajoelhou-se na calçada e beijou os pés de Virginia. Por ela o episódio estaria encerrado, mas ele foi à caça. Ficou subentendido que fora também movido pelo desejo de entregar-lhe os originais, tanto dos Poemas ingleses (ainda em português) quanto do rascunho de The Foolish Bird, sequer esboçado. Queria alguém "para polir a linguagem que ele não dominava". Virginia, que vinha de um casamento frustrado e de pequena duração, confessa: "acabei gostando muito dele". E ressalva que "não era completamente humano" e até "via coisas que para os outros não estavam lá".

De fato, além de intérprete, Ovalle era fio-terra de manifestações sobrenaturais. Ao sair de uma sessão de cinema, com lágrimas nos olhos declarou a quem o acompanhava: "O caminho do céu está cheio de anjinhos japoneses". No dia seguinte, estavam nos jornais fotos de milhares de crianças mortas num cataclismo no Japão. Da mesma clave foi o comentário aleatório que fez a quem estava ao seu lado: "Jorge já foi". Naquele momento, o poeta Jorge de Lima tinha acabado de morrer.

O casamento de Jayme e Virginia ocorreu em 1951 no Mosteiro de São Bento, a lua-de-mel foi no Quitandinha e, daí por diante, ele se afastou dos hábitos boêmios. Passou a sair cada vez menos à noite. Recebia poucos em seu apartamento no Leblon. A reflexão não era mais de bar: "O importante não é saber se a pessoa gostou do uísque, mas se o uísque gostou da pessoa”. Em 1952 nasceu Mariana e ele "viveu apaixonadamente a vida de pai", garantia Virginia. A roda boêmia se reduziu. Como sabia beber, não ficava bêbado. Acordava lépido. Não tirava férias. "Às vezes ficava eufórico", "via outras coisas", acrescentou Virginia. Com a mudança para o apartamento em Copacabana, o fim começou a se aproximar: "Não sabia nadar, não entrava na água, não tirava os sapatos na areia”. Virgínia: "Estranho, boníssimo. Muito infantil”.

Sobre o poeta, dizia Virginia: "era de breves cintilações, apenas", completando que se falava "de um homem que nunca foi à escola, e que por pouco não tinha sido analfabeto". Não por acaso, Ovalle certa vez ressalvou (em causa própria) que "o importante é o poeta, não a obra". E Virginia completou mais tarde o sentido da frase: "Como poeta e como músico, tinha capacidade de dar inspiração aos outros". Ao se aproximar dos 60 anos, não falava mais de The Foolish Bird e dos Poemas ingleses, confiados ao zelo de Virginia para saírem de uma 
idéia concebida em português e voarem alto com a garantia da língua inglesa. Nunca mais.

Virgínia não precisou de se proteger com interpretações, mas, mineiro por nascimento e convicção, Werneck a relaciona bem com o mistério contagiante de episódios dotados de inesgotável vida própria. Pouco terá ficado de fora do que é conhecido (ou presumido) do acervo ovalliano, além da seqüência de episódios que excedem a fronteira da coincidência e não invadem o campo da ciência. $\mathrm{O}$ autor despertou para o personagem por efeito das referências à criatividade potencial e à originalidade de se expressar (de que vivia seu personagem), desde quando ainda não confirmara (nem confirmaria) a que viera ao mundo. Cedeu à tentação e ao desafio de levantar a história completa, de acesso facilitado pelos laços de admiração e relação com os que teriam o que contar. Fernando Sabino foi o elo decisivo (antes de morrer) e aparece como discípulo do poeta que não fazia versos.

Manuel Bandeira foi amigo desde as primeiras referências, quando o toque sobrenatural ainda não marcava o perfil de Ovalle. Foi parceiro no Azulão, cuja letra tem sua assinatura. No começo, o anedótico teve precedência na vida do personagem, sob a forma de originalidade nos hábitos de vida e nas características que o identificariam do começo ao fim. Mas não prevaleceu. O compositor levantou vôo curto e o poeta também não passou de bissexto, na escala classificatória de Bandeira. Salvaram-se para a posteridade 33 composições musicais, pela mesma razão que o levou a acabar órfão das musas por falta de disposição para articular palavras escritas e notas musicais.
O último capítulo tem como personagem a filha Mariana, sob o signo das mesmas coincidências, mas sem as sombras que pairavam sobre o pai vivo. A filha dá o toque delicado à lembrança que ficou de Jayme Rojas de Aragón y Ovalle, apenas Jayme Ovalle. O livro termina sem nada mais por acrescentar. Nada faltou para encerrar, não a lenda, mas a história de um homem e a sua circunstância.

Wilson Figneiredo é colunista do Jornal do Brasil (Rio de Janeiro, RJ). @ - wilson@figueiredo.com 